\title{
Representações sociais da AIDS para estudantes de Psicologia
}

\author{
Noêmia Soares Barbosa Leal, I Angela Elizabeth Lapa Coêlho ${ }^{I I,} \star$ \\ ${ }^{I}$ Universidade Federal da Paraíba, João Pessoa, PB, Brasil \\ ${ }^{I I}$ Centro Universitário de João Pessoa, João Pessoa, PB, Brasil
}

\section{Resumo}

A Síndrome da Imunodeficiência Adquirida (Aids) configura-se como fenômeno social que ultrapassa o conceito de doença, constituindo-se em estigma para aquele que tem o diagnóstico. É um problema de saúde pública que afeta faixas etárias, classes socioeconômicas e sociedades indistintamente, a Aids constitui temática de estudo e investigação inesgotável. Esta pesquisa apoia-se na teoria das Representações Sociais e tem como objetivo analisar as representações da Aids, de saúde e de doença para 20 estudantes de Psicologia. A análise dos dados se deu por meio da análise de conteúdo, e os resultados apontaram que o conhecimento sobre a Aids nem sempre resulta em comportamentos mais seguros; as representações revelaram preconceito e estereotipias, identificando a Aids como a doença do outro e se fazendo presentes no imaginário social, dificultando a convivência social com as pessoas com HIV/ Aids. Estes resultados sugerem uma reflexão sobre as campanhas educativas e preventivas.

Palavras-chave: representações sociais; AIDS; saúde.

\section{Social representation of AIDS to Psychology students}

\begin{abstract}
Acquired Immunodeficiency Syndrome (Aids) is a social phenomenon that goes beyond disease concept, constituting a stigma for those with the diagnosis. As a public health problem that affects age groups, socioeconomic classes and societies indiscriminately, Aids is an endless area of study and research. This research is based on the social representations theory, focusing on the subjective content representations of social groups affected by the interaction between scientific knowledge and common sense. The objective of this research was to analyze social representations of Aids, health and disease for 20 Psychology students. Data analysis was done through content analysis, and results showed that knowledge about Aids does not always result in safer behaviors and social representations of Aids showed prejudice and stereotypes, identifying Aids as a disease of the others and present in social imagination, hindering social interaction with people with HIV/ Aids. These results suggest a reflection on educational and preventive campaigns.
\end{abstract}

Keywords: social representations; AIDS; health.

\section{Introdução}

Atualmente, a Aids configura-se como um grave problema de saúde pública no que se refere às repercussões da doença e também pelo crescente aumento do número de casos, sendo uma das principais doenças que está na origem das elevadas taxas de mortalidade em todo o mundo. Devido ao aumento de casos de contaminação pelo Vírus da Imunodeficiência Humana (HIV) entre jovens, várias pesquisas têm sido desenvolvidas no intuito de compreender seus estilos de vida para, a partir dessa compreensão, propor modos de prevenção eficazes (AYRES, 2002; RUZANY; MEIRELLES, 2009; PIMENTEL; SILVA; SALDANHA, 2010; BARROS; COLAÇO, 2013).

Nesta pesquisa, parte-se da perspectiva da Teoria das Representações Sociais, por ser uma abordagem teórica que possibilita a apreensão do conteúdo subjetivo e da manifestação do pensamento dos grupos sociais influenciados pela interação entre conhecimento e ambiente. A teoria das Representações Sociais tem sido amplamente aplicada em pesquisas e estudos no campo da saúde-doença e notadamente da Aids, que por ser um fenômeno social complexo que envolve diversos aspectos além dos epidemiológicos, necessita ser estudada por meio de uma teoria que abarque a compreensão dos conceitos elaborados pelos grupos para o processo saúde-doença, contágio, prevenção e percepção de vulnerabilidade.

\footnotetext{
* Endereço para correspondência: Centro Universitário de João Pessoa. Campus Universitário BR 230 Km 22 - Água Fria. CEP. 58053-000 - Joao Pessoa, PB - Brasil.E-mail:noemia.barbosa@hotmail.com, coelho.angela1@gmail.com
}

O presente trabalho teve como objetivo analisar as Representações Sociais da Aids, assim como da saúde e doença para estudantes do Curso de Psicologia, tendo em vista que cada vez mais os psicólogos fazem parte de equipes interdisciplinares e as suas Representações Sociais poderão ter influência em como eles abordam as pessoas e elaboram suas estratégias de intervenção relacionadas à prevenção, diagnóstico e tratamento de pessoas com o HIV/Aids. A relevância do estudo é que trabalhando com alunos, existe a possibilidade de identificarmos a forma como eles representam a Aids, trazendo para a discussão essas representações e as implicações que elas terão sobre suas práticas futuras. Pelo fato de a pesquisa ter sido desenvolvida com alunos dos últimos períodos do curso, os resultados encontrados podem também indicar como esses futuros profissionais estão sendo formados e promover estratégias que despertem o interesse para pesquisas nessa área.

\section{Considerações sobre a teoria das Representações Sociais}

No âmbito da saúde, as Representações Sociais são estudadas com objetivos diversos, dentre os quais está à compreensão de sua influência na dinâmica da doença e da saúde. Em estudo realizado por Grazzinelli et al. (2005), o conceito das Representações Sociais é apontado como sendo largamente aplicado em estudos sobre o processo de saúde e doença no Brasil e é ressaltada a importância dos saberes do senso comum na relação dos indivíduos com a doença, uma vez que vivenciar uma do- 
ença implica invariavelmente em relacionar-se conflituosamente com o social, pois não raro, a doença interfere no contexto em que o indivíduo está inserido, mas por outro lado, constitui uma forma de auto-conhecimento, pois o indivíduo aprende a superar-se para enfrentar a doença. Os autores ressaltam a necessidade de uma articulação entre Representações Sociais e a experiência da doença para o indivíduo, pois a doença tanto é manifesta cognitiva como afetivamente, sendo importante compreender como a doença é elaborada culturalmente para, a partir de intervenções educativas, levar os indivíduos a reconhecê-la como algo anormal e disfuncional e que, portanto precisa de intervenção para garantia da saúde.

Assim, para que o conhecimento sobre o adoecer e o prevenir-se seja eficaz na postura de mudança de comportamento, torna-se imprescindível que o indivíduo elabore as informações recebidas e as tornem significativas para si. É bem verdade que em toda e qualquer cultura existem sempre pontos de tensão, como por exemplo, o surgimento de uma doença como a Aids, que apontam a existência de falhas na organização do conhecimento e trazem consigo o desconforto do não-familiar. A ausência de sentido percebida nesses momentos, como prescreve Moscovici (2009), faz surgir novas representações do fenômeno a fim de torná-lo familiar e reestabelecer o sentido de estabilidade. Portanto, em situações de conflito, as Representações Sociais ganham espaço privilegiado para significação de eventos, que nada mais são do que as formas de criação coletiva.

\section{Representações da Aids}

A Aids, desde seu surgimento, representa um fenômeno social que ultrapassa o conceito de doença e constitui um estigma para aquele que tem o diagnóstico positivo. Por razão dos homossexuais terem sido os primeiros a manifestar a doença no ocidente, a sociedade relacionou rapidamente a Aids a homossexualidade, tentando atribuir uma relação de causa-efeito para o qual nem a comunidade científica tinha respostas. A partir dessa representação, os homossexuais passaram a ser temidos como um grupo de risco (BARBARÁ et al., 2005).

No entanto, desde o primeiro caso da Aids no Brasil, em meados de 1980, houve uma variação no perfil das populações acometidas pela doença, o que contribuiu para modificar crenças equivocadas sobre as populações que estavam suscetíveis ao contágio e deixou claro que qualquer pessoa está vulnerável ao adoecimento, uma vez que a Aids não atinge apenas alguns segmentos da população, mas está relacionada com as chances de exposição dos indivíduos, com fatores sócio-culturais e econômicos, com crenças socialmente construídas, com papéis de gênero dentre outros aspectos (PIMENTEL; SILVA; SALDANHA, 2010; GARCIA; SOUZA, 2010).

Para Barbará et al. (2005), a evolução da Aids no Brasil é delimitada por três fases caracterizadas por sua expansão. $\mathrm{Na}$ fase inicial, o foco estava direcionado aos infectados pelo HIV, aos grupos ditos de risco, principalmente os homossexuais. Esse estigma impediu a condução de ações mais amplas no campo da saúde. A segunda fase caracteriza-se pela exposição ao vírus via drogas injetáveis que atingiu de modo crescente os heterossexuais. Nessa fase, houve a substituição do termo grupo de risco para comportamento de risco. Na terceira e atual fase, a preocupação está centrada na suscetibilidade dos indivíduos em geral ao vírus, reforçando a idéia de que todos estão passíveis ao adoecimento, o que, segundo Saldanha et al. (2008a) faz surgir o conceito de vulnerabilidade, ampliando a visão acerca das formas de contaminação.

A adoção do conceito de vulnerabilidade considera a possibilidade de exposição das pessoas ao adoecimento, como consequência de um conjunto de aspectos que ainda que se refiram ao indivíduo, também o posiciona em relação ao coletivo. Quanto à vulnerabilidade individual, há dois mecanismos implicados, um de ordem cognitiva e outro de ordem comportamental, sendo o primeiro alusivo a quantidade e qualidade da informação que o indivíduo dispõe e a competência de elaborá-la e o segundo relativo à capacidade, habilidade e interesse para transformar essas preocupações em atitudes e ações protegidas e protetoras. A vulnerabilidade, portanto, está relacionada aos comportamentos que oportunizam a pessoa a contrair doenças, ao grau de consciência que estas têm sobre seus comportamentos e ao efetivo poder que podem exercer para transformá-los (AYRES et al., 2003; SALDANHA et al., 2008b).

No ponto de vista de Mann et al. (1992), a antítese para a vulnerabilidade é o empoderamento, ou seja, é preciso que as pessoas estejam em condições de aprender e de responder a programas educativos e de prevenção, por exemplo. Os elementos fundamentais para que políticas educativas e de prevenção sejam efetivas incluem os domínios de informação e educação; saúde e serviços sociais e o desenvolvimento social de suporte a população. Assim, o empoderamento pressupõe que o indivíduo tenha garantias de acesso a uma série de recursos antes de tomar qualquer atitude ou mesmo mudar seu comportamento.

Nesse sentido, os programas de educação em saúde não devem se restringir a propagação de informações à população, antes, devem integrar valores, costumes, modelos, símbolos sociais e representações de saúde e de doença que conduzam a formas específicas de condutas e práticas. Para que os programas de educação em saúde sejam eficazes, é importante combinar intervenção com acolhimento, de modo a reconhecer o protagonismo dos sujeitos no trajeto até a efetuação das estratégias de prevenção e tratamento (AYRES, 2002; FELICIANO, 2005; GRAZZINELLI et al., 2005).

Atualmente, percebe-se que o fenômeno do HIV/ Aids tem um histórico de representações bastante diversificado e caracterizado por fortes investimentos afetivos, como preconceitos, medo, sofrimento, o que torna a temática tão rica quando analisada sob o enfoque das Representações Sociais, uma vez que o conteúdo subjetivo e as construções de saber coletivo são valorizados. Torna-se imprescindível, portanto atentar para as formas de vulnerabilidade e prevenção da epidemia, que embo-

Fractal, Rev. Psicol., v. 28 - n. 1, p. 9-16, 2016 
ra esteja apresentando tendências de estabilização, ainda constitui uma doença devastadora e que traz graves implicações para saúde e vida social do indivíduo.

\section{Método}

\section{Participantes}

A pesquisa foi qualitativa, do tipo não-probabilística por conveniência, composta por um total de 20 estudantes universitários do Centro Universitário de João Pessoa - UNIPÊ, da cidade de João Pessoa-PB, correspondendo a sete alunos do sétimo período; sete alunos do oitavo período e seis alunos do nono período. Entre os participantes, $70 \%$ eram do sexo feminino e $30 \%$ do sexo masculino, com idade entre 20 e 50 anos e média de idade de 28,15 anos. Quanto ao estado civil, 25\% dos participantes declararam-se casados e $75 \%$ solteiros.

A identificação das representações e conhecimentos acerca da Aids é importante no desenvolvimento de programas educativos específicos para esse público, de modo a reforçar os aspectos positivos detectados e trabalhar com os negativos, preparando-os para o autocuidado, assim como para instrumentalizá-los para o exercício de atividades profissionais condizentes e minimizando a possibilidade de atitudes preconceituosas e estigmatizantes para com as pessoas com HIV/Aids.

\section{Instrumento}

Os participantes responderam a um questionário estruturado e a uma entrevista. O questionário para caracterização da amostra teve seu roteiro elaborado pela autora com base nos estudos de Diclemente, Zorn e Temonshok (1986) e Owens (1995) e apresentou perguntas fechadas de caráter sócio-demográfico, contendo questões como sexo, idade, e estado civil. A segunda etapa foi composta por uma entrevista estruturada, contendo questões abertas, que abordaram os objetos propostos nesse estudo, a saber: as Representações Sociais sobre saúde, doença e Aids.

\section{Procedimentos e aspectos éticos}

No desenvolvimento desta pesquisa, foram resguardados todos os procedimentos formais exigidos pela Resolução do Conselho Nacional de Saúde (CSN) n. 196/1996 (BRASIL, 1996). O projeto da pesquisa foi aprovado pelo Comitê de Ética em Pesquisa do Centro Universitário de João Pessoa - UNIPÊ e as entrevista só foram realizadas em condições de privacidade e mediante a assinatura de um Termo de Consentimento Livre e Esclarecido pelo(a) entrevistado(a).

\section{Análise dos dados}

A análise do conteúdo das entrevistas seguiu os seguintes passos: transcrição das entrevistas gravadas na íntegra; leitura atenta do material para identificar os temas surgidos em cada questão; escolha das palavras que sintetizam o conteúdo das falas dos participantes e escolha dos trechos dos relatos que representavam os temas elencados.

As categorias das respostas foram organizadas em tabelas para uma melhor visualização e para a análise dos dados, foi utilizada a técnica da análise temática categorial de Bardin (2002), que se baseia em operações de desmembramento do texto em unidades, ou seja, em descobrir os diferentes núcleos de sentido que constituem a comunicação e posteriormente, foi realizado o seu reagrupamento em classes de categorias. Os conteúdos obtidos foram analisados à luz da teoria das Representações Sociais (MOSCOVICI, 1978).

\section{Resultados e Discussão}

A análise das entrevistas revelou que o objeto de investigação da pesquisa está pautado nos elementos da realidade social, nos modos de conhecimentos e saberes do senso comum que surgem e se legitimam na conversação interpessoal. A escuta do material gravado foi acompanhada pela leitura de dados disponíveis na literatura atual, de forma a auxiliar na compreensão das falas dos participantes e da emergência dos conteúdos construídos socialmente. Os conteúdos identificados foram organizados nos quadros na medida em que foram surgindo nas falas dos participantes, não tendo relação com a frequência de vezes que surgiram e a forma de apresentação dos resultados será pelas perguntas feitas aos participantes e os conteúdos por eles transmitidos.

\section{O que é Aids?}

Inicialmente, foi questionado aos participantes o que é a Aids para eles e a partir dos relatos, realizou-se uma classificação das respostas dadas quanto ao seu conteúdo, conforme está descrito no Quadro 1.

\section{Quadro 1: Categorização das representações da Aids de acordo com os participantes.}

\begin{tabular}{c|l}
\hline Ouestão & \multicolumn{1}{c}{ Conteúdos identificados } \\
\hline 1 PARA VOCÊ, O QUE É & 1.1 Doença sexualmente transmissível e \\
AIDSectocontagiosa. \\
& 1.2 Doença que causa sofrimento e preconceito. \\
& 1.3 Doença de pessoas irresponsáveis e sem informacão. \\
\hline
\end{tabular}

O primeiro conteúdo identificado nas respostas refere-se à compreensão da Aids como uma doença sexualmente transmissível e infectocontagiosa, como pode ser observado nas falas a seguir:

Aids é uma doença sexualmente transmissivel, transportada através das relações sexuais, através de secreções vaginais ou através dos espermas secretados nas relações sexuais.

Aids é uma doença né?! infectocontagiosa de alto risco para quem a tem.

Essas falas sugerem que o conhecimento dos estudantes de Psicologia sobre a Aids ainda está muito relacionado à transmissão por via sexual, o que alerta para a possibilidade de que outras situações de risco possam ser ignoradas, favorecendo assim o aumento das chances de exposição ao vírus, como o compartilhamento de objetos cortantes, contato com materiais contaminados, entre outras situações que também representam os mesmos riscos para contaminação. O perigo de desconsiderar outras formas de contaminação está, segundo Paiva et al. (2002), em que a Aids aproveita as brechas abertas por crenças, valores e culturas sexuais para se espalhar e invadir corpos de homens e mulheres. 
Associada a esta ideia, a Aids também foi relacionada ao sofrimento, relacionado ao preconceito direcionado as pessoas diagnosticadas com Aids, como revelam as seguintes falas:

Eu acho que Aids é uma doença é, que ela causa muito sofrimento pra pessoa que tem, que é portadora do vírus e que é carregada de muito preconceito assim, por parte das pessoas.

Aids é um [...] seria a doença do vírus do HIV né!?, agora no caso da repercussão social tá mais ligada a parte de preconceitos e exclusão social das pessoas que são portadoras.

Apesar de todo conhecimento hoje disponível sobre as formas de transmissão, as pessoas com HIV/Aids ainda são muito discriminadas e isoladas do convívio social, como revelam os relatos. A Aids, além de ser uma doença que traz repercussões físicas e psicológicas, também se configura como um fenômeno social que surge acompanhado de preconceitos, estigmas socialmente construídos, medo irracional, afastamento, e outros valores intimamente ligados as representações sociais dessa doença (CASTANHA et al., 2006).

Por outro prisma, Lepri (2007) situa o preconceito e a discriminação como um reflexo da necessidade que a sociedade tem em manter o equilíbrio pela identificação e exclusão da diferença. Assim, tudo aquilo que não é familiar torna-se ameaçador para o grupo e tende a ser afastado de modo a manter a coesão do mesmo, como também explica a teoria das Representações Sociais. É importante ressaltar ainda, que as primeiras representações da doença remetiam a promiscuidade sexual de grupos de risco determinados, o que reforçou o preconceito e estigmatizou fortemente algumas pessoas a partir de suas práticas sexuais, comportamentos e atitudes.

A atribuição da Aids às pessoas irresponsáveis ou sem informação ainda permeia as representações que as pessoas fazem da doença, como pode ser observado nas falas a seguir:

[...] às vezes as pessoas acabam sem querer adquirindo a Aids porque não conhecem.

Aids pra mim é uma doença muito séria, onde ela pode ser pega naqueles irresponsáveis que não se previnem direitinho.

Nesse sentido, pode-se questionar se há realmente falta de informação sobre o que seria a Aids, sobre as formas de transmissão do vírus e prevenção, tão difundidos na mídia. O que pode ocorrer é que mesmo havendo programas de educação sexual direcionados aos jovens, estes muitas vezes têm discurso moralista e não proporcionam um espaço para que a comunicação seja desenvolvida para despertar a consciência e a mobilização efetiva dos jovens ao uso da camisinha (PAIVA et al., 2002).

A literatura também tem demonstrado que o conhecimento sobre a doença e os riscos de adoecer não é suficiente para resultar em uma mudança de comportamento, antes é preciso que o indivíduo elabore as informações recebidas, tornando-as significativas para si, que se reconheça como vulnerável ao adoecimento e que se empodere das informações sobre prevenção e promoção de saúde.

\section{Você se considera vulnerável ao HIV?}

A segunda questão refere-se a auto-percepção de vulnerabilidade ao HIV dos participantes e dentre os conteúdos identificados, destacam-se os seguintes:

\begin{tabular}{|c|c|}
\hline Ouestão & Conteúdos identificados \\
\hline $\begin{array}{l}2 \text { VOCÊ É VULNERÁVEL } \\
\text { AO HIV? }\end{array}$ & $\begin{array}{l}\text { 2.1 Sim, pois é sexualmente ativa e já praticou ou pratica } \\
\text { sexo sem camisinha. } \\
\text { 2.2 Não, pois assume comportamentos seguros. } \\
2.3 \text { Não, pois só tem relação com um parceiro. }\end{array}$ \\
\hline
\end{tabular}

O primeiro conteúdo identificado demonstra a percepção dos participantes de que é uma pessoa é vulnerável a contaminação pelo vírus pelas condições de ser sexualmente ativa, de já ter praticado ou praticar sexo sem uso de preservativos, como demonstram as falas:

Sim, eu creio que todo ser humano ele é vulnerável né?! até porque assim, quando a pessoa começa a ter relacionamento sexual, ele começa a ser vulnerável.

Considero, porque eu não uso camisinha com meu parceiro.

Sim, porque eu já tive relações sexuais sem camisinha.

Nesse sentido, embora os participantes demonstrem estar cientes do risco real de contaminação, as falas podem indicar comportamentos sexuais desprotegidos, o que se leva a questionar porque as pessoas, mesmo reconhecendo sua própria vulnerabilidade ao adoecimento, ainda se engajam em práticas que oferecem risco a sua saúde e não adotam as medidas de proteção que reconhecem ser eficazes, como o uso da camisinha. Estudos desenvolvidos por Silva e Vargens (2009) e Garcia e Souza (2010), apontam que um dos fatores determinantes para o uso do preservativo é a confiança depositada no parceiro, decorrente da presunção de fidelidade, notadamente quando há união estável, matrimonial ou em namoros mais duradouros, de modo que o uso do preservativo está associado, em geral, às relações sexuais eventuais.

Silveira et al. (2002) observaram em seu estudo, que apesar de conscientes de sua vulnerabilidade, muitos indivíduos persistiam em práticas de risco. Considerando essa disparidade entre conhecimento das formas de prevenção e a não adoção de cuidados nas práticas sexuais, surge a necessidade de se conhecer melhor a percepção de vulnerabilidade das pessoas com relação adoecer por conta de uma DST, de modo que seja possível instrumentalizar formas de intervenção preventivas mais eficazes.

Foram também identificadas falas que revelam que os participantes não se consideram vulneráveis a contaminação pelo HIV uma vez que afirmaram assumir comportamentos seguros e evitar situações de risco.

[...] eu sou cuidadosa, então assim, se eu não tivesse esse cuidado, poderia acontecer comigo também, só que eu tenho os meus cuidados, nas relações sexuais eu uso preservativo, geralmente, uso, quando eu vou pra manicure eu uso meu alicate, assim, se eu não fosse uma pessoa cuidadosa, poderia acontecer comigo.

Não, eu não acho que eu esteja vulnerável pela questão de não ter relações sexuais, sem [...] a questão de preservati- 
vos e também uso de drogas ou de estar mesmo vulnerável a alguma situação que ofereça risco.

Por meio dessas falas, percebe-se que os participantes representam o uso do preservativo nas relações sexuais, o uso de alicates pessoais e o de situações que ofereçam risco como atitudes preventivas diante da doença, e revelam também que o perigo da doença está sempre fora, é sempre externo ao próprio indivíduo, ou seja, só há chances de ocorrer se ele se identificar com grupos mais vulneráveis, como usuários de drogas, como exemplifica uma das falas. Oltramari (2003) enfatiza que há sempre uma necessidade de cuidado com os outros, externos ao grupo, que podem ter o vírus, diferentemente da percepção que tem de si mesmo e do reconhecimento de si como invulnerável ao adoecimento.

A questão do não uso de preservativos ressurge relacionada ao motivo de ter um parceiro sexual fixo, que por si só já é considerado um fator de proteção. O conteúdo das falas abaixo revela que as participantes casadas se sentem protegidas contra a Aids, pois sentem também que o casamento é um espaço em que a fidelidade e segurança estão presentes. Contudo, é preciso considerar que o casamento por si só pode não garantir uma imunidade as DSTs, sendo importante também, as práticas que seus parceiros podem eventualmente adotar fora da instância do casamento, como exemplifica o estudo de Guerriero et al. (2002), em que alguns homens casados relataram não usar preservativo nas relações extraconjugais por considerarem as amantes como parcerias estáveis.

Não, não me considero porque eu só tenho relação com o meu marido não tive relação com outros parceiros.

[...] eu não uso realmente preservativo, nunca usei com o parceiro que eи vivo, mеи esposo, foi o теи primeiro parceiro.

Na concepção de Oltramari (2003), na medida em que a Aids está diretamente relacionada às questões da sexualidade, podem-se perceber claramente as diferenças existentes entre homens e mulheres neste aspecto, onde as crenças e os valores acerca da sexualidade masculina e feminina serão diretamente influenciados pelas representações sociais que se tem delas. Quando se trata de intimidade, estas representações não podem ser desprezadas devido ao fato de que elas atuam como mediadoras sociais para os comportamentos de prevenção, sendo importante considerar os estudos de Ayres (2003), Garcia (2006), Sousa, Espírito Santo e Motta (2008) e Silva e Vargens (2009).

Nesse sentido, é como se os relacionamentos sem parceria fixa e feita fora dos limites do casamento, representassem maiores chances de contaminação pelo HIV, enquanto que o relacionamento estabelecido com um parceiro fixo, com o qual se compartilha sentimentos de confiança e exclusividade na parceria sexual representasse menores chances de exposição ao risco. Nesse sentido, é importante que as pessoas compreendam não só o que é a Aids, mas que também compreendam o que é saúde e doença, as chances que cada um tem de adoecer e como manter-se saudável.

Fractal, Rev. Psicol., v. 28 - n. 1, p. 9-16, 2016

\section{O que é saúde?}

Foi também questionado o sentido de saúde segundo a compreensão dos participantes, destacando-se os conteúdos contidos no Quadro 3:

Quadro 3: Categorização do conceito de saúde para os participantes.

\begin{tabular}{c|l}
\hline Ouestão & \multicolumn{1}{c}{ Conteúdos identificados } \\
\hline 3 PARA VOCÊ, O QUE É & 3.1 Bem-estar biopsicossocial. \\
SAÚDE? & 3.2 Ausência de doença. \\
3.3 Ter qualidade de vida. \\
\hline
\end{tabular}

O primeiro conteúdo identificado situa a saúde como bem-estar biopsicossocial e remete a definição da Organização Mundial de Saúde. Embora a pergunta tenha sido formulada na tentativa de conduzir os participantes a responderem conforme sua própria concepção de saúde, a maior parte das falas trouxe uma definição pronta e possivelmente elaborada no contexto da universidade.

Pra mim eu acho que a saúde cai bem na definição da OMS, do bem-estar biopsicossocial, eu acho que estar bem consigo, é estar bem com o seu biológico é é estar bem com a sociedade.

Bom, eu tenho aprendido aqui no curso que saúde é o bem- estar físico, psico e social de um ser humano, então desde que você esteja bem psicologicamente, fisicamente, você como ser humano, você tá com saúde.

Essas falas, ao situarem aspectos subjetivos como determinantes da saúde, sugerem a superação do modelo biomédico, no qual os aspectos físicos da saúde e doença tinham lugar de destaque na determinação do estado de saúde. Nesse sentido, é dada relevância a outros aspectos da vida que influenciam diretamente o estado de saúde, compreendido em sua dimensão biopsicossocial, para o qual o bem-estar subjetivo e a inserção social contribuem substancialmente. O estudo de Colussi (2009) encontrou dados semelhantes quando questionado a um grupo de crianças o que era estar com saúde.

Por outro lado, embora o caráter social da saúde pareça hoje inquestionável, ainda foi encontrada, na fala de um dos participantes, a compreensão da saúde pautada num modelo médico tradicional, que situa a saúde e doença unicamente como resultante de um processo biológico, como exemplifica a fala:

É a ausência de doença.

Por meio dessa fala, depreende-se o processo biológico como predominante na determinação da saúde, parecendo não haver espaço para considerar o caráter social, atualmente reconhecido como atuante e determinante do estado saudável. Na perspectiva de Lebrão (1997), quando os padrões de comportamento, a reação do indivíduo aos estímulos de seu meio, o acesso aos meios de promoção da saúde e prevenção de doenças são considerados, é possível reconhecer como a história do indivíduo assume importância em sua condição biológica e influencia as chances de adoecer ou de manter-se saudável.

Para Colussi (2009), quando a saúde é definida segundo o modelo biomédico, em que a ausência de sintomas físicos indica o estado saudável, é transmitida uma 
visão simplista e potencialmente perigosa se consideramos doenças que inicialmente podem apresentar períodos assintomáticos. No caso da Aids, essa compreensão pode influenciar as pessoas a não adotar medidas preventivas ou se diagnosticadas portadoras do vírus, não aderir ao tratamento. É preciso, portanto, relacionar outros elementos implicados na saúde, como os aspectos sociais e modelos comportamentais, entre outros.

Outras falas associam saúde à qualidade de vida:

Saúde é um conceito bem amplo. Saúde pra mim é uma questão não só de ausência de doença, mas a questão da qualidade de vida né?! [...] a qualidade de vida interfere diretamente na nossa saúde né?! Então ter uma boa qualidade de vida, ter uma boa vida né?

[...] é algo muito completo, como agente sempre fala, eu acho que saúde tá muito ligado a questão de qualidade de vida, quanto melhor sua qualidade de vida, melhor sua saúde.

Essas falas remetem a compreensão da saúde de um modo atual que até ultrapassa o entendimento da saúde como definida pela OMS, pois identificam a saúde como um estado de bem-estar e qualidade de vida, processos estes que são dinâmicos e socialmente produzidos. $\mathrm{Na}$ concepção de Buss (2000), a questão da saúde ultrapassa a prevenção de doenças ou a tentativa de prolongar a vida e compreende que os meios e situações que ampliem a qualidade de vida estejam assegurados para que o indivíduo tenha ampliada sua autonomia, suas escolhas e seu padrão de bem-estar.

A qualidade de vida é um estado subjetivo e que se relaciona ao bem-estar, sendo que esse conceito é definido pelo indivíduo com base em sua compreensão do que seria gozar de saúde e ter qualidade de vida, mas também se relaciona aos valores socialmente compartilhados do que significam esses construtos.

\section{O que é doença?}

A última pergunta procurou identificar como os participantes compreendem o sentido de doença. A partir das respostas foram identificados um total de três conteúdos significantes, como podem ser observados no Quadro 4:

Quadro 4: Categorização do conceito de doença para os participantes.

\begin{tabular}{|c|c|}
\hline Questão & Conteúdos identificados \\
\hline \multirow{3}{*}{$\begin{array}{c}4 \text { PARA VOCÊ, O QUE É } \\
\text { DOENÇA? }\end{array}$} & 4.1 Um mal-estar geral. \\
\hline & 4.2 Ausência de saúde. \\
\hline & 4.3 Ser dependente. \\
\hline
\end{tabular}

O primeiro conteúdo identificado sobre o que seria doença situa esta como um mal-estar geral e contrapõem-se ao conceito de saúde, mas de toda forma, faz uma referência ao conceito de saúde preceituado pela OMS, como revelam as falas abaixo:

Doença é você está ruim fisicamente, está mal fisicamente, mental ou psicologicamente ou espiritualmente no caso, isso define a doença.

Doença é o desequilíbrio, que ela pode ser tanto físico, como psicológico e social.
Essas falas conceituam a doença não apenas como um mal-estar decorrente de sintomas físicos ou biológicos, mas já consideram o processo de doença como tendo influências também de aspectos comportamentais, subjetivos e espirituais que interferem negativamente na totalidade do indivíduo e afetam seu equilíbrio. Estes relatos indicam uma referência direta a fenômenos endógenos e exógenos que podem ocasionar enfermidades, sugerindo uma superação do modelo biomédico, dominante por tanto tempo nas práticas em saúde, e uma compreensão mais abrangente, que abarca o processo saúde e doença como resultante de fatores diversos que incluem fatores biológicos, mas também sociais e subjetivos.

Por outro lado, foram identificadas duas falas que ainda situam a doença no modelo biomédico, como também foi identificado em tópico anterior, quando se questionou sobre a saúde.

Eu acho que a doença, eu vou ser bem óbvia, é a ausência de saúde, né!? Eu acho que é um mal-estar em que a pessoa tá passando, algo assim mesmo, a ausência de saúde eu definiria.

A ausência de saúde.

A compreensão da doença como meramente ausência de saúde pode ser uma demonstração de uma compreensão limitada desse processo, sugerindo que uma parcela da população ainda pauta seus comportamentos de promoção de saúde ou prevenção de doenças, observando unicamente fatores biológicos, o que se torna alarmante ao considerarmos que muitas doenças resultam de condições ambientais desfavoráveis e de padrões comportamentais prejudiciais a saúde, o que pode posicionar estas pessoas em situações potenciais de vulnerabilidade. Por fim identificou-se que estar doente também é compreendido pela impossibilidade de o indivíduo realizar suas atividades diárias sozinho, como são reveladoras as falas:

Doença pra mim é você depender dos outros, ficar acamado, os outros ter que cuidar de você, né!? porque existem vários tipos de doença que você pode ser você mesma, ir ao banco, fazer as coisas pessoais e outras que você não, isso pra mim é uma doença.

é não poder exercer com satisfação aquilo que você tem de fazer.

Dados semelhantes foram encontrados por de Lima (2005), no qual os participantes de seu estudo representaram a doença justamente como sendo a dependência de algo ou alguém para que se tornasse possível desenvolver atividades diárias. No sentido dessas falas e considerando doenças como a Aids que podem apresentar períodos assintomáticos e muitas vezes a pessoa nem sabe que está doente, depreende-se que o reconhecimento do estado de doença está ligado a manifestações clínicas visíveis e que limitam o ir ou vir da pessoa, trazendo prejuízos funcionais. Já se a pessoa doente não apresenta sintomas observáveis e que limitem o exercício de atividades, é como se essa doença não incomodasse ou oferecesse grandes prejuízos para a pessoa. 


\section{Considerações Finais}

Diante da discussão teórica e dos dados encontrados e discutidos na realização desta pesquisa, percebemos como a Teoria das Representações Sociais pode contribuir para a compreensão dos conhecimentos construídos e partilhados socialmente. Assim, avaliar conhecimentos sobre saúde, doença e Aids à luz das Representações Sociais, permite perceber que muitos conhecimentos oriundos do senso comum se mantêm fortalecidos no imaginário popular, norteando e justificando ações, sem qualquer embasamento científico, o que fortalece muitos mitos e preconceitos, notadamente em torno da Aids.

Neste sentido, quando se trata de futuros psicólogos que poderão integrar equipes interdisciplinares na área da saúde, compreendemos que se estes não estiverem bem informados a respeitos das DSTs em geral, e da Aids especificamente, poderão lidar com os processos de saúde, doença, prevenção, diagnóstico e tratamento de modo inadequado, trazendo implicações negativas no trato com os pacientes.

Os dados coletados revelaram que, embora a modernidade tenha sido presenteada por novos modos e meios de comunicação de massa, possibilitando para uma grande parte da população o acesso, a democratização da informação, o espaço para novos atores sociais e a ampliação do processo psicossocial do conhecimento, ela não resultou necessariamente em uma apropriação efetiva desses conhecimentos, tão difundidos pela mídia. Nesse sentido, é preciso compreender como as pessoas recebem, constroem sentido e aplicam as informações sobre saúde e doença na vida prática.

Desse modo, embora as informações sobre o processo saúde-doença e sobre a Aids tenham avançado no sentido de haver um maior conhecimento científico sobre as formas de prevenção e fatores que facilitam a contaminação e o adoecimento, que tentam desvincular as antigas representações da doença como próprias de grupos específicos da sociedade, o que se percebe é que ainda se faz presente, para os participantes deste estudo, as velhas representações, preconceitos e atitudes em relação à pessoa com HIV/Aids, o que dificulta o manejo da doença e a convivência social com o portador do vírus.

Por outro lado, embora uma parte dos participantes tenha demonstrado conhecimentos corretos quanto à transmissão da Aids e ao risco que eles mesmos correm de contaminação, esses conhecimentos não se traduzem em comportamentos mais seguros ou contínuos de acordo com os relatos. Quando os jovens dizem saber alguma coisa sobre a Aids, o que se observa é que esse conhecimento é relativo, pois de modo geral, eles não são capazes de assumir na prática sexual as informações que dizem ter de um modo constante.

É preciso ainda repensar os papéis de gênero, assim como as expectativas sociais que se tem deles, para que o uso da camisinha se torne mais presente e contínuo nos relacionamentos. Também a relação de oposição entre fidelidade e o não uso de camisinha deve ser desmistificada, para que as tendências de feminização e heterossexualização da Aids não sejam ainda mais fortalecidas.
Garcia e Souza (2010) recomendam que as questões de gênero sejam contempladas pelas políticas públicas de saúde e que sejam investidos esforços no combate ao preconceito da pessoa com HIV/Aids, além de distribuir preservativo feminino como uma alternativa para as mulheres que não conseguem negociar o uso do preservativo masculino com seus parceiros.

Embora haja muitos estudos sobre a Aids, suas representações e manifestações em populações jovens, é preciso ainda que os conhecimentos produzidos por estes estudos sejam apropriados por instituições responsáveis por campanhas educativas, preventivas e de promoção de saúde, a fim de que suas contribuições não fiquem restritas ao campo teórico-literário, mas antes, que sejam articuladas na prática e assim possam ter muito mais aproveitados e difundidos os conhecimentos produzidos. O contexto acadêmico também precisa se apropriar da temática, incluindo-a no currículo dos cursos que formam profissionais que poderão atuar com a população acometida por DSTs/Aids, tal como no Curso de Psicologia, de modo que estes profissionais estejam capacitados para lidar com este universo a partir de uma postura profissional e científica.

Nesse sentido, sugerimos que novas pesquisas sejam desenvolvidas com essa temática e que visem compreender a relação controversa entre os conhecimentos que os jovens dizem ter sobre modos de prevenção do HIV e a não instrumentalização desse saber na prática, o que tem sido responsável pelo aumento do número de jovens acometidos pela doença.

\section{Referências}

AYRES, J. R. C. M. Práticas educativas e prevenção de HIV/Aids: lições aprendidas e desafios atuais. Interface Comunicação, Saúde, Educação, [S.1.], v. 6, n. 11, p. 11-24, ago. 2002

AYRES, J. C. R. M. et al. O conceito de vulnerabilidade e as práticas de saúde: novas perspectivas e desafios. In: CZERESNIA, D.; FREITAS, C. M. de. (Org.). Promoção da saúde: conceitos, reflexões, tendências. Rio de Janeiro: FIOCRUZ, 2003. p.117-139.

BARBARÁ, A. et al. Contribuições das representações sociais ao estudo da AIDS. Interação em Psicologia, Curitiba, v. 9, n. 2, p. 331-339, 2005.

BARDIN, L. Análise de conteúdo. Tradução de Luís Antero Reto e Augusto Pinheiro. Lisboa: Edições 70, 2002.

BARROS, J. P. P.; COLAÇO, V. de F. R. "Meu prazer agora é risco": sentidos sobre sexualidade entre jovens de um grupo sobre saúde. Fractal: Revista de Psicologia, Niterói, v. 25, n. 1, p. 59-80, jan./abr. 2013.

BRASIL. Ministério Público. Conselho Nacional de Saúde. Resolução 196/96: Diretrizes e Normas Regulamentadoras de Pesquisas Envolvendo Seres Humanos. 1996. Disponível em: $<$ http://pfdc.pgr.mpf.mp.br/atuacao-e-conteudos-de-apoio/ legislacao/saude/resolucoes/Resolucao CNS 196.1996>. Acesso em: 20 jun. 2012.

BUSS, P. M. Promoção da saúde e qualidade de vida. Ciência \& Saúde Coletiva, [S.1.], v. 5, n. 1, p. 163-177, 2000. 
CASTANHA, A. R. et al. Aspectos psicossociais da vivência da soropositividade da HIV nos dias atuais. PSICO, Porto Alegre, v. 37, n. 1, p. 47-56, 2006.

COLUSSI, C. B. As representações sociais de saúde e doença para crianças de uma escola em Campo Grande/MS. 2009. Dissertação (Mestrado em Psicologia)-Universidade Católica Dom Bosco, Campo Grande, 2009.

DICLEMENTE, R. J.; ZORN, J; TEMOSHOK, L. Adolescents and AIDS: a survey of knowledge, attitudes and beliefs about AIDS in San Francisco. American Journal of Public Health, [S.1.], v. 76, n. 12, p. 1443-1445, 1986.

FELICIANO, K. V. de O. Prevenção da AIDS entre os jovens: significados das práticas e os desafios à técnica. Revista Brasileira de Saúde Materno Infantil, [S.1.], v. 5, n. 4, p. 429438, 2005.

GARCIA, S. Homens na Intimidade: masculinidades contemporâneas. Ribeirão Preto, SP: Holos, 2006.

GARCIA, S.; SOUZA, F. M. de. Vulnerabilidades ao HIV/Aids no Contexto Brasileiro: iniquidades de gênero, raça e geração. Saúde Sociedade, São Paulo, v. 19, supl. 2, p. 9-20, 2010.

GRAZZINELLI, M. F. et al.Educação em saúde: conhecimentos, representações sociais e experiências da doença. Caderno de Saúde Pública, Rio de Janeiro, v. 21, n. 1, p. 200-206, 2005.

GUERRIERO, I. et al. Masculinidade e vulnerabilidade ao HIV de homens heterossexuais, São Paulo, SP. Revista de Saúde Pública, São Paulo, v. 36, n. 4 supl., p. 50-60, ago. 2002.

LEBRÃO, M. L. Estudos de morbidade. São Paulo: Universidade de São Paulo, 1997.

LEPRI, P. M. F. Aspectos psicológicos do adolescer com HIV/ Aids: estudo de caso. Dissertação (Mestrado)-Faculdade de Ciências e Letras de Assis, Universidade Estadual Paulista "Júlio de Mesquita Filho", Assis, 2007. Disponível em: <http:/ acervodigital.unesp.br/handle/unesp $/ 172338$ ?locale $=$ pt_BR $>$ Acesso em: 12 jul. 2011.

LIMA, A. C. G. G. de O. D. de. As Representações Sociais de saúde e doença para os portadores de diabetes melito que procuram o serviço de diagnóstico e prevenção da retinopatia diabética. 2005. Dissertação (Mestrado em Psicologia) Universidade Católica Dom Bosco, Campo Grande, 2005.

MANN, J. et al. Aids in the World: a global report. Cambridge, MA: Harvard University Press, 1992.

MOSCOVICI, S. A Representação Social da Psicanálise. Rio de Janeiro: Zahar; 1978.

MOSCOVICI, S. Representações sociais: investigações em psicologia social. 6. ed. Petrópolis, RJ: Vozes, 2009.

OLTRAMARI, L. C. Um Esboço sobre as Representações Sociais da AIDS nos Estudos Produzidos no Brasil. Caderno de pesquisa interdisciplinar em ciências humanas, [S.1.], n. 45, p. 1-17, 2003.

OWENS, S. Attitudes toward and knowledge of AIDS among social work students. Health and Social Work, [S.1.], v. 20, n. 2, p. 110-121,1995.

PAIVA, V. et al. Jovens e adolescentes em tempos de AIDS: reflexões sobre uma década de trabalho de prevenção. Psicologia USP, São Paulo, v. 13, n. 1, p. 55-78, 2002.

PIMENTEL, P. L. B.; SILVA, J.; SALDANHA, A. A. W. Uso do preservativo e vulnerabilidade à AIDS em adolescentes: implicações para a interiorização da epidemia na Paraíba. In: HIV/AIDS VIRTUAL CONGRESS, 10., 2010, Lisboa. VIH/ SIDA em países de língua portuguesa.

RUZANY, M. H.; MEIRELlES, Z. V. Tráfico de drogas, masculinidade, relação de gênero e risco de DST/AIDS. Adolescência e Saúde, [S.1.], v. 6, n. 1, p. 9-14, 2009.

SALDANHA et al. Representações sobre a Aids na velhice por coordenadores de grupos da terceira idade. Psico-USF, [S.1.], v. 13, n. 1, p. 95-103, 2008a.

SALDANHA et al. Comportamento sexual e vulnerabilidade à Aids: um estudo descrito com perspectiva de práticas de prevenção. DST - Jornal Brasileiro de Doenças Sexualmente Transmissiveis, [S.1.], v. 20, n. 1, p. 36-44, 2008b.

SILVA, C. M.; VARGENS, O. M. C. A percepção de mulheres quanto à vulnerabilidade feminina para contrair DST/HIV. Revista da Escola de Enfermagem da USP, São Paulo, v. 43, n. 2, p. 401-406, 2009.

SILVEIRA, M. F. et al. Autopercepção de vulnerabilidade às doenças sexualmente transmissíveis e Aids em mulheres. Revista de Saúde Pública, São Paulo, v. 36, n. 6, p. 670-677, 2002.

SOUSA, M. C. P.; ESPIRITO SANTO, A. C. G.; MOTTA, S. K. A. Gênero, vulnerabilidade das mulheres ao HIV/Aids e ações de prevenção em bairro da periferia de Teresina, Piauí, Brasil. Saúde e Sociedade, São Paulo, v. 17, n. 2, p. 58-68, 2008.

Recebido em: 3 de julho de 2012 Aceito em: 1 de dezembro de 2015 